\title{
High-voltage DC converter for solar power station
}

\author{
Mohamed Qawaqzeh ${ }^{1}$, Roman Zaitsev ${ }^{2}$, Oleksandr Miroshnyk ${ }^{3}$, Mykhailo Kirichenko ${ }^{4}$, \\ Dmytro Danylchenko ${ }^{5}$, Liliia Zaitseva ${ }^{6}$ \\ ${ }^{1}$ Department of Engineering, Al-Balqa Applied University, Jordan \\ 2,4,6 Materials for Electronics and Solar Cells Department, National Technical University “KhPI”, Ukraine \\ ${ }^{3}$ Department of Power Supply and Energy Management, Kharkiv National Technical University of Agriculture, Ukraine \\ ${ }^{5}$ Department of Electric Power Transmission, National Technical University “KhPI”, Ukraine
}

\begin{tabular}{|c|c|}
\hline Article Info & ABSTRACT \\
\hline Article history: & In the article the circuit design solution of DC-DC regulated resonant \\
\hline Received Apr 17, 2020 & $\begin{array}{l}\text { converter has been proposed for using with hybrid photovoltaic modules } \\
\text { which has cooling equipment and solar concentrators in order to maximize }\end{array}$ \\
\hline Revised Jun 10, 2020 & electric power generating by such module. By using computer simulation \\
\hline Accepted Jul 28, 2020 & $\begin{array}{l}\text { based on multiple iterations algorithm we significantly increase the accuracy } \\
\text { of determining the resonance circuit optimal parameters for build up DC-DC }\end{array}$ \\
\hline Keywords: & $\begin{array}{l}\text { converters to work in a wide range of electric powers. Based on optimal } \\
\text { values of the resonance LLC scheme parameters, achived by numerical }\end{array}$ \\
\hline Buck-boost converter & calculation it can be show high values of electrical energy transformation \\
\hline Circuit design & $\begin{array}{l}\text { efficiency for photovoltaic energy station equipped with high efficiency } \\
\text { hybrid photovoltaic modules. Implementation of microprocessor-based }\end{array}$ \\
\hline Photovoltaic module & control into design of DC-DC back-boost converters create a new possibility \\
\hline Power take-off system & to build control algorithms for increase reliability and conversion efficiency, \\
\hline Solar energy & $\begin{array}{l}\text { rapid and precision stabilization of maximum power point, implementation } \\
\text { network monitoring of photovoltaic modules, converters itself and the whole } \\
\text { photovoltaic station parameters. }\end{array}$ \\
\hline
\end{tabular}

This is an open access article under the CC BY-SA license.

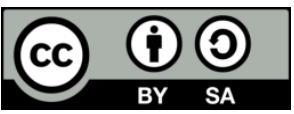

\section{Corresponding Author:}

Liliia Zaitseva,

Materials for Electronics and Solar Cells Department,

National Technical University “KhPI”, Ukraine.

Email: zaitsev@khpi.edu.ua

\section{INTRODUCTION}

Solving the problem of photovoltaic power plants ecocnomy competitiveness in comparson with energy produced by carbon-based sources is a prerequisite for solar energy using in growing scale. In order to find the decision of this task, it has been developed the design of hybrid photovoltaic module (PVM) based on single-crystal silicon solar cells with a cooling equipment in order to maximize electric power generating by such module. Using the modules with a cooling equioment in a photovolaic station design leads to below the solar cells (SC) operating temperature $[1,2]$ which allows to maximize he amount of electricity generated by station and also to increase solar cells lifetime, while equipped modules by solar radiation concentration systems, allows to achieve practically twice increase the power which produced by photovoltaic modules. Assembling of such photovoltaic modules on the tracker, a solar radiation monitoring device, will allow increase the electrical power produced by the photovoltaic station minimum on the $30 \%$. At the same time, development power take-off system on the base of classic elements for conversion direct current produced by a PVM into industrial frequency electricity leads to new problem. The most important component of the power take-off system is the DC-DC back-boost converter, needed to increase the amplitude of produced by the PVM voltage for ensure their minimal losses during transmission and conversion [3, 4]. Since the 
electrical power produced by the PVM depends from the solar power daytime change, the optimization of DC-DC converter and the power take-off system design solutions should be carried out taking into account the entire range of converted electrical power. The basic principles of schematic design choice when creating an optimized DC-DC converter with the function of maximum PVM power take-off are to achieve the highest conversion efficiency, ensuring a long operational time and economic ratio of the technical characteristics to the components cost, taking into account a wide range of operating temperatures [5].

Finding out the optimal design of all parts which compose the system to transform energy from PVM into industrial frequency electrical energy should maximize photovoltaic power plants efficiency and give the possibility to reach their competitiveness onto world market by complex of energy and economic parameters. Based on the above mentioned main schematis design principles, it was analyzed and selected schematic designs for DC-DC converter, which will allow to optimize its technical characteristics and increase efficiency [6-8]. The buck boost pulse DC converter is a series connection of the step-down and step-up converters. It is possible to use a common throttle and filter capacitors. In order to increase the efficiency in the buck-boost converter, a bridge circuit with synchronous rectification is often used [9]. The efficiency of the up and down pulse converters takes the maximum value (more than 99\%) when the input voltage is equal to the output. Thus, for the step-down converter the efficiency in our case [2] will be maximal at an input voltage of $23 \mathrm{~V}$, and for the step-up converter at an input voltage of $42 \mathrm{~V}$ (the minimum and maximum voltage corresponds to the PVM maximum power point take-off [2]). The greater the difference between the input and output voltage, the lower the efficiency. Using step-down converter will be maximally effective at the highest and a step-down converter at the lowest ambient temperature. The serial connection of the step-up and step-down converters allows you to select an input voltage level at which the converter efficiency is greater than $99 \%$, for example a rated input voltage is about $30 \mathrm{~V}$. In this case, the efficiency at the edge of the converter input voltage range will be smaller, but the high efficiency values range will expand. Another advantage is the maximum ripple current in the throttle when using the topology of buck boost pulse DC converter described in [10,11], which allows to using throttle with a smaller overall size [9].

\section{RESULTS AND DISCUSSION}

\subsection{Choice of schematic design solution}

An example of efficiency dependence for up-, down- pulse controller and buck boost pulse DC converters is shown on Figure 1, and the topology of buck boost pulse DC converter is shown on Figure 2.

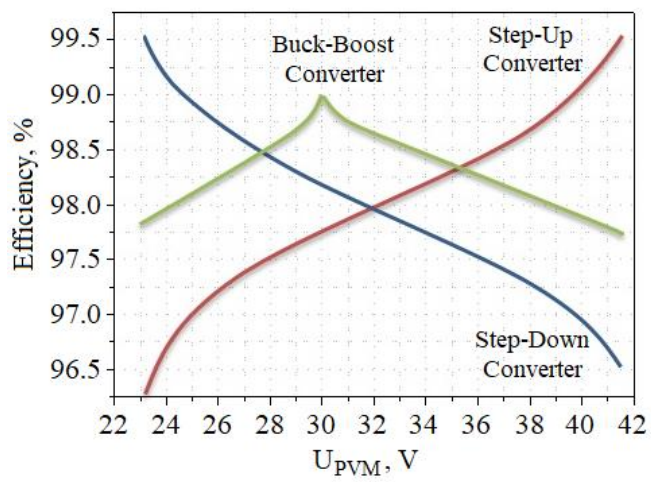

Figure 1. The dependence of the converter efficiency from input voltage

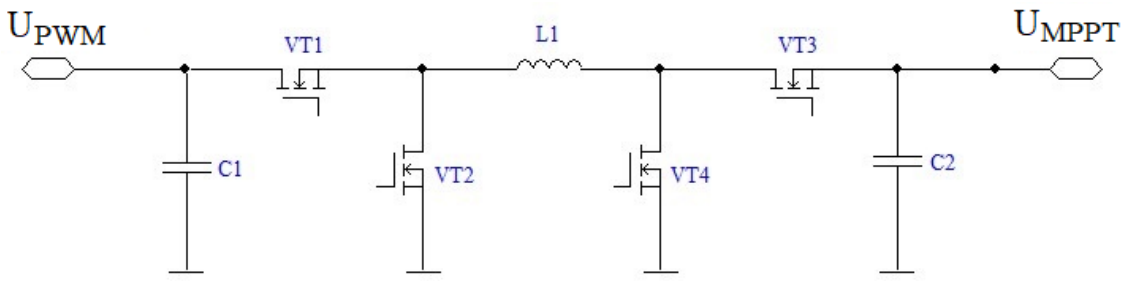

Figure 2. Basic topology of buck boost pulse DC converter 
The buck boost pulse DC converter is built using only one inductor and a set of VT1 - VT4 transistors for up and down stages. In this case, to efficiency increase and reduce the load on the passive components in each of operating modes, we need use only its own cascade; the second must be disabled. This is achieved by using 100\% duty cycle for VT1 transistor (VT2 off) while using the step-up cascade, and $100 \%$ duty cycle for VT3 transistor (VT4 off) when the step-down cascade is active. The buck boost pulse DC converter topology can also be designed by multiphase [12]. The variant of topology, presented on the Figure 2, is the most optimal for PVM maximum power take-off function implementation without galvanic isolation of the input and output circuits. Taking into account the implementation of galvanic isolation, the most optimal solution $[13,14]$ is the bridge resonance converter topology (BRC), which is shown on Figure 3. Typically, most of modern resonant converters have resonant LLC link structure (serial connection of two inductors and capacitance) [15] and working in zero-voltage switching mode [16, 17] (when used as MOSFET transistors). One of the inductors is represented by the throttle L1, the other by the throttle L2. In practice, the throttle L1 is the sum of transformer TR1 and external throttle (may be absent) inductances and the throttle L2 is the inductance of the transformer TR1 magnetization. Resonant capacitance is represented by capacitor $\mathrm{C} 1$. Transistor conductivity losses are proportional to the transformer primary current square, so, despite the larger transistors number in the BRC topology, the transistor conductivity losses are two times lower: the total resistance of the transistor open channel is twice as large and the primary transformer current square is four times less in the BRC topology. At the input voltage from $23 \mathrm{~V}$ to $42 \mathrm{~V}$ and input power up to $300 \mathrm{~W}$, the most perspective between topologies still BRC. However, in case of multiphase mode implementation, this choice is not so obvious. One from BRC drawback`s is the lack of specialized circuits (PWM controllers) for transistor control, but this is not a disadvantage when implementing digital control system. Significant reactive current in a low-load resonant converter is also not a disadvantage in the unregulated resonant converter design, but in the regulated one is a significant obstacle [18]. Thus, when choosing between a non-resonant and a resonant converter for systems with an input voltage from $23 \mathrm{~V}$ to 42 $\mathrm{V}$ and a maximum power up $300 \mathrm{~W}$, we should consider the necessity of converter transmission ratio tuning.

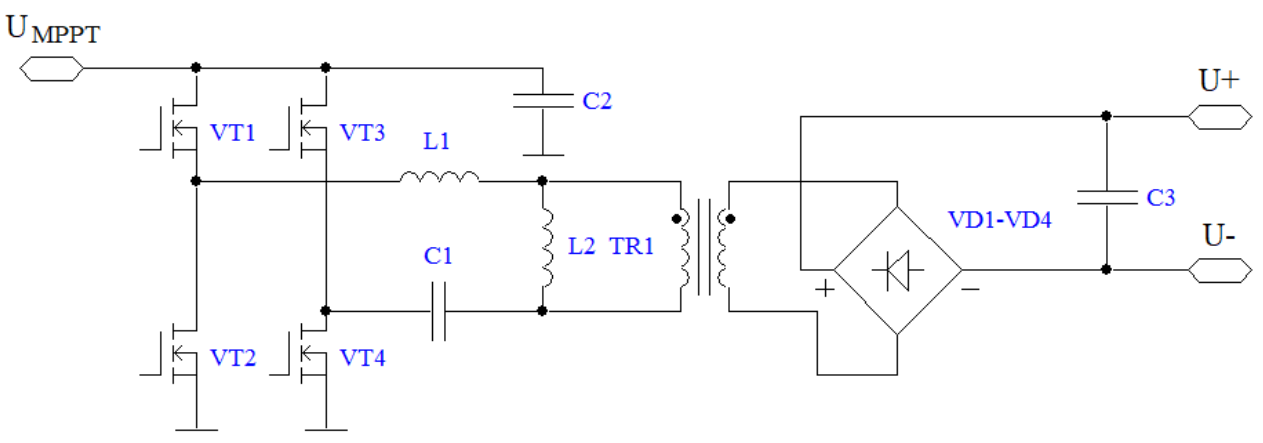

Figure 3. Basic topology of bridge resonant LLC converter

The implementation of maximum power take-off function is usually due to using two-phase twotransistor backflow converter (TTBC) or adjustable resonant LLC converter [19]. The TTBC variant topology is shown on Figure 4. This topology of a single-stroke converter is interesting because it has a higher efficiency than the classical backflow converter due to transformer inductance energy recuperation [20]. Multiphase variant of this topology eliminates another negative property of backflow inverters - the high value of output pulsations. The TTBC topology unambiguously loses by efficiency to the resonant LLC converter, but provides a better implementation of PVM maximum power take-off algorithm due to the almost complete absence of load parameters (600 V -700 V DC inverter) influence on converter`s input parameters. That is, the output DC power supply does not affect the PVM maximum power tracking mode. This feature applies to all backflow converters. Another advantage of this topology is the ability to work on to the short circuited output without high-speed protective circuits using due to unused energy recuperation back into the input circuit [19]. The disadvantages of this topology include the number of phases to reduce the output pulsations and rejection from electrolytic capacitors using, the presence of upper arm transistors control circuit (drivers), as well as the transformers overall dimensions and cost.

In addition, using of adjustable resonant LLC converter allows to obtain higher efficiency values (Figure 5) [21], the disadvantages of controlled conversion include a narrow regulation range and low efficiency at low load when implementing a wider regulation range. However, single cascade using, in comparison with the multi-cascade TTBC scheme, reduces the number of elements and the cost of the 
converter [22]. At in-series TTBC cascades connection, the total efficiency will be equal to each cascade efficiency product, which means that converter efficiency will be lesser than each of its cascade's efficiency. Thus, the best circuit design for single-stage converter with the PVM maximum power take-off function and galvanic isolation, in terms of efficiency in a wide input parameters range to the components cost ratio, provides the using of bridge resonant LLC converter topology. However, this topology is most demanding for the correct choice of resonance link parameters and converter operating modes [23].

The proposed schem design ensures the maximally effective converter operation in wide diapasone of operating parameters, and also easy of transistors control system realizatiob, including possibility of specialized integrated circuits using. The high efficiency value minimizes the difficulty with converter cooling. For housing, it is easy to use standart sealed solution from aluminum alloy. Converter operation parameters - maximal values of input power and voltage, was chosen in order to corresponds to single PVM parameters, which allow to using significantly cheap transistors and electronic components of common design, and minimize power components heating.

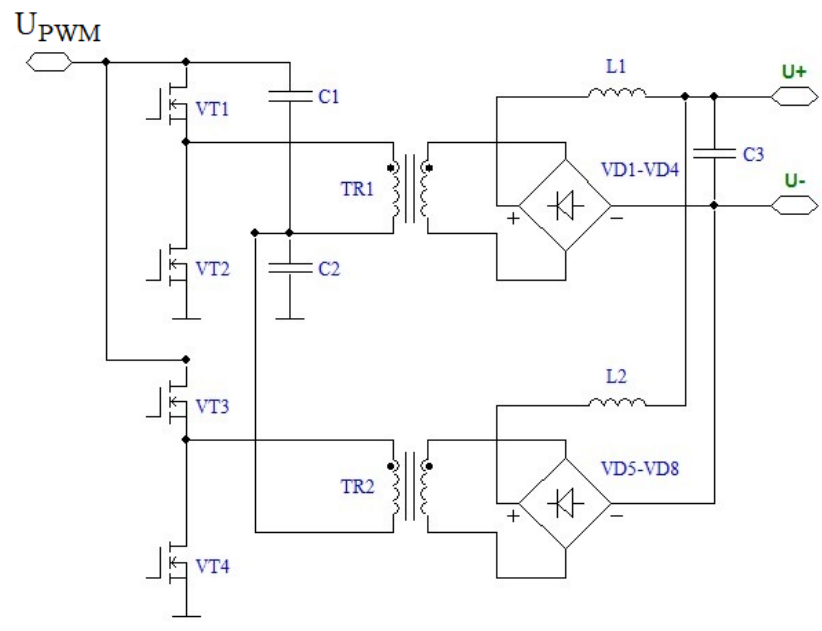

Figure 4. Basic topology of a two-phase two-transistor backflow converter

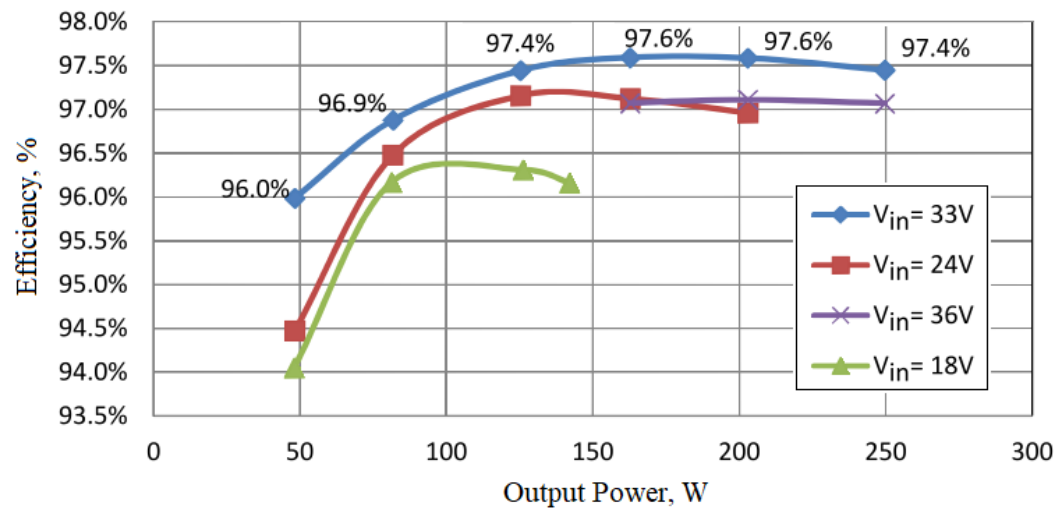

Figure 5. The dependence of bridge resonant LLC converter efficiency from output power at different input voltages

\subsection{DC-DC back-boost scheme design and parameters calculation}

Coefficient of conversion for tunable scheme of bridge converter:

$G=K \cdot n$

Where $\mathrm{K}$ is the coefficient of conversion for resonance LLC scheme; $\mathrm{n}$ is ratio of turn's number in secondary and primary windings of the TR1 transformer [24]. Because resonance converter reachs maximum 
of their efficiency at $\mathrm{K}=1$, we can obtain $\mathrm{n}$ in terms of maximization converter efficiency at their standart operation regime:

$$
n=\frac{U_{\text {in.nom }}}{U_{\text {out.nom }}}=\frac{30}{630}=\frac{1}{21}
$$

In this $\mathrm{U}_{\text {in.nom }}$ is the nominal voltage value which goes into the converter; $\mathrm{U}_{\text {out.nom }}$ is the nominal voltage value which goes out from the converter. Coefficient of conversion for resonance LLC scheme will reach their maximum $K_{\max }$ in case minimum of input voltage $\left(U_{\text {in.min }}\right)$ and maximum of output $\left(U_{\text {out.max }}\right)$, so the minimum of $\mathrm{K}_{\min }$ we will have in case of inverse situation with values of working parameters:

$$
\begin{aligned}
& K_{\max }=n \cdot \frac{U_{\text {out } \max }}{U_{\text {in.min }}}=\frac{1}{21} \cdot \frac{700}{23} \approx 1,45 \\
& K_{\text {min }}=n \cdot \frac{U_{\text {out.min. }}}{U_{\text {in.max }}}=\frac{1}{21} \cdot \frac{600}{42} \approx 0,68 .
\end{aligned}
$$

In order to obtain the main resonance LLC scheme parameters, we build up the equivalent scheme of our resonance scheme [24, 25]. Coefficient of conversion for such equivalent scheme, can be calculated as follows:

$$
K=\left|\frac{U_{\text {in }}}{U_{\text {out }}}\right|=\frac{F_{x}^{2}(m-1)}{\sqrt{\left(m F_{x}^{2}-1\right)+F_{x}^{2}\left(F_{x}^{2}-1\right)^{2}(m-1)^{2} Q^{2}}}
$$

In this $Q=\frac{\sqrt{\frac{L_{r}}{C_{r}}}}{R_{a c}}$ is the quality factor; $R_{a c}=\frac{8}{\pi^{2}} n^{-2} \frac{U_{o u t}}{I_{\text {out }}}$ is value of resistor which serves as a load; $\mathrm{U}_{\text {in }}$ is voltage value which goes into the converter; $\mathrm{U}_{\text {out }}$ is voltage value which goes out from the converter; $\mathrm{I}_{\text {out }}$ is current on the output converter contacts; $F_{x}=\frac{f_{s}}{f_{r}}$ is transistors switching frequency (normalized); $\mathrm{f}_{\mathrm{s}}-$ is transistors in converter switching frequency; $f_{r}=\frac{1}{2 \pi \sqrt{L_{r} C_{r}}}$ is scheme resonance frequency; $\mathrm{L}_{\mathrm{r}}$ is resonance inductance; $\mathrm{C}_{\mathrm{r}}$ is resonance capacitance; $m=\frac{L_{r}+L_{m}}{L_{r}}$ is ratio of the total inductance on the circuit input to the resonance inductance; $\mathrm{L}_{m}$ is transformer magnetization inductance.

Minimal value of resistor which serves as a load $R_{a c . m i n}$ we will have with minimal voltage value which goes out from the converter and maximal power $\left(\mathrm{P}_{\text {in.max }}\right)$ produced by converter and also when converter efficiency will reach their maximal value up to $98 \%$ :

$$
R_{\text {ac.min }}=\frac{8}{\pi^{2}} n^{2} \frac{U_{\text {out.min }}{ }^{2}}{P_{\text {in.max }} \cdot \eta}=\frac{8}{3.14^{2}} \cdot 0.047619^{2} \cdot \frac{600^{2}}{300 * 0.98} \approx 2.25 \Omega .
$$

Carried out the correct calculations of the resonance scheme parameters will lead us to optimal converter parameters. For this calculation we use the new algorithm which by the numerous iterations give us the possibility to precision calculate the LLC resonance scheme working parameters [25]. On the base of combination, the preliminary calculation which completed by computer simulation was implemented the possibility to give precision calculation results and minimize the time for such type calculations. Maximal value of voltage which goes into the converter corresponds to module maximum heating at power of illumination $200 \mathrm{~W} / \mathrm{m}^{2}$, in this case minimum of power onto converter input $\left(\mathrm{P}_{\mathrm{in.min}}\right)$ does not exceed:

$$
P_{\text {in.min }}(23 \mathrm{~V}) \leq 23 \mathrm{~V} \cdot I_{\text {in.nom }} \cdot \frac{200}{1000} \frac{\mathrm{W}}{\mathrm{m}^{2}}=37,6 \mathrm{~W}
$$

Based on the wide range of operation parameters in DC-DC back-boost converter design, the feature of resonant converter tuning also the dependence of efficiency from LLC circuit parameters, we can define the influence of voltage which goes into the converter on the values of maximum electrical power generated by converter which give the possibility to predict the maximal value of converter efficiency and choose the most effective type of connection to solar module. The specified dependence of the maximal electric power from voltage which goes into the converter has shown on Figure 6, a. From [26] well known that for maximal value of output current we should have the maximal Q. In the other hand the output current maximal values correspond to minimal voltage which goes out from the converter and maximum electric power, generated by convertor. The calculated value of resistor which serves as a load $R_{a c . m i n}=2.25 \Omega$ matches to maximal value of Q for LLC scheme, and the maximal coefficient of conversion for resonance scheme $\mathrm{K}_{\max }=1.45$ needs to 
input electric power value up to $50 \mathrm{~W}$ and voltage which goes out from the converter up to $700 \mathrm{~V}$. Based on the formulae for $R a c$, the minimum of resistor which serves as a load value $\mathrm{R}_{\mathrm{ac} \text {.min }}$ can be calculated in case of voltage which goes into the converter reaches up to $23 \mathrm{~V}$ :

$$
R_{\text {ac.min }}(23 V)=\frac{8}{3.14^{2}} \cdot 0,047619^{2} \cdot \frac{600^{2}}{50 \cdot 0.98} \approx 13.5 \Omega .
$$

Using the above mentioned algorithm, we build diagram and calculate values of resonance scheme parameters for $100 \mathrm{kHz}$ resonance frequency which shown on Figure 6, b and presented in Table 1.

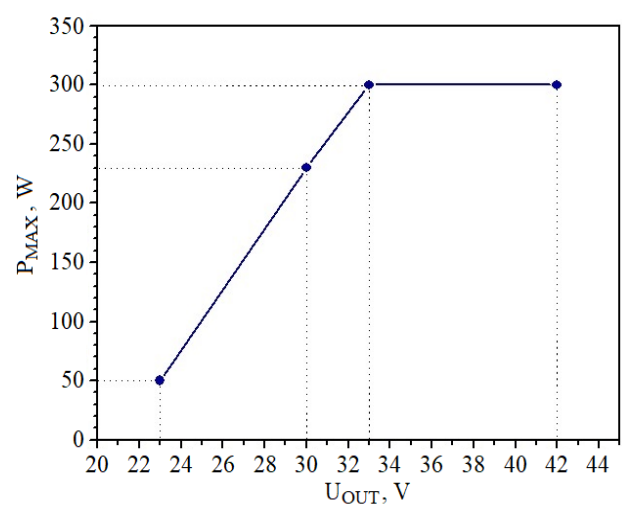

(a)

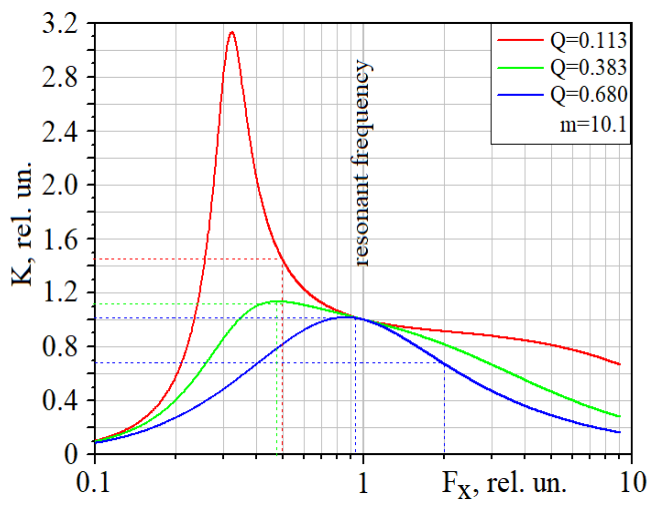

(b)

Figure 6. The dependence of DC-DC converter maximum output power from input voltage (a) and the dependence of LLC circuit transmission coefficient from normalized frequency at given figure of quality values (b)

Table 1. Working parameters of resonance scheme

\begin{tabular}{ccccccc}
\hline$U_{i n}, \mathrm{~V}$ & $P_{i n}, \mathrm{~W}$ & $K_{\max }$ & $K$ & $R_{a c . \max }, \Omega$ & $Q_{\max }$ & $F_{x}$ \\
\hline 23 & 50 & 1,45 & 3,13 & 13,5 & 0,113 & 0,33 \\
30 & 230 & 1,11 & 1,134 & $3,995^{*}$ & $0,383^{*}$ & $0,48^{*}$ \\
33 & 300 & 1,01 & 1,026 & 2,25 & 0,68 & 0,86 \\
42 & 300 & 0,79 & 1,026 & 2,25 & 0,68 & 0,972 \\
\hline
\end{tabular}

*Presented $\mathrm{R}_{\mathrm{ac} \text {.min }}$ matches to maximal voltage which goes out from the converter and $\mathrm{K}_{\max }$.

Taking into account the resonance capacitance of $0.94 \mu \mathrm{F}$ at $110.7 \mathrm{kHz}$ frequency we calculate the resonance inductance $-\mathrm{Lr}=2.2 \mu \mathrm{H}$ and having $m=10.1$ calculate the transformer magnetization inductance $\mathrm{Lm}=20 \mu \mathrm{H}$.

\subsection{DC-DC converter making}

The functional and principal electric scheme of the DC-DC converter shows on Figure 7. Voltage from PVM goes to the converter input and digital microcontroller MC installed to optimize the parameters of converter and for control of transistors switching. The signal from MC goes to VT1 - VT4 transistors gates through Dr.1 - Dr.4 drivers. According to bridge scheme we have a simultaneous transistor switching on every bridge part. Microcontroller and driver powering up by specialized DC converter which ensure stabilizing and stepping-down of input voltage. Using of microcontroller ensures the continuous monitoring of current, generated by module by means of shunt resistance R3 and amplifier, and voltage outgoing from module by using divided scheme based on R1 - R2 resistors. At their G1 and G2 pins the microcontroller generate two impulses which are counter-phases and neede to set up the frequency of transistors switching and establish the delay («dead») time for bridge diagonals switching [27]. Midpoint value of voltage on VT1 - VT2 transistors half-bridge using for implementing adaptive «dead» time principe needed to ensure maximal values of converter efficiency, goes on to microcontroller comparator pins from divided scheme based on R4 - R5 resistors. The VD1 rectifyer connects with N3 winding of transformer connected in order to control the nominal voltage value which goes out from the converter and also it using in algorithmic detection of resonance LLC scheme operating mode to prevent changing their current flow regime into the 
capacitive. The necessity of such resonance scheme operating regimes control is valuable at converter start and in case of fast changes of voltage value which goes out from the converter - a DC network $600-700 \mathrm{~V}$.

The resonance LLC scheme consists from choke, capacitor and a transformer - L1, C1, T1, respectively. The resonance inductance combines from L1 inductance and T1 scattering inductance. Voltage from transformer output needs to be restifying by scheme on the base of VD2 diode C3 capacitor. After rectifier the DC voltage goes directly on to converter. Hybrid module maximum power point searching and tracking ensured on the base of perturbation and Observation (P\&O) algoritm by microcontroller [28, 29]. For implementing this algorithm the microcontroller firstly calculates the PVM putput power, and at second act it makes a small change of converter input resistance through the variation of transistors switching frequency, as a result the voltage on the converter input also changes, and MC carry out the power calculation - if it increase - the MC will continue to changing input voltage in established direction up to the moment when power began to decrease. Using of microcontroller allow to implement a P\&O algorithm for searching and tracking the PVM maximum power point, and also to realize adaptive «dead» time, and continious monotoring in order to finding the capacitive nature of the bridge load. Also implementing microcontroller in converter design will allow integrate it into monitoring network by using cable or wireless connection, like RS-485 or ZigBee protocols, in order to continuous monitoring of modules parameters, ensuring information about the failure, etc [30].

Figure 8 shows the DC-DC converter based on proposed schematic design for direct installation on photovoltaic modules, which allow to maximize the efficiency of electricity generation from solar iiradiation.

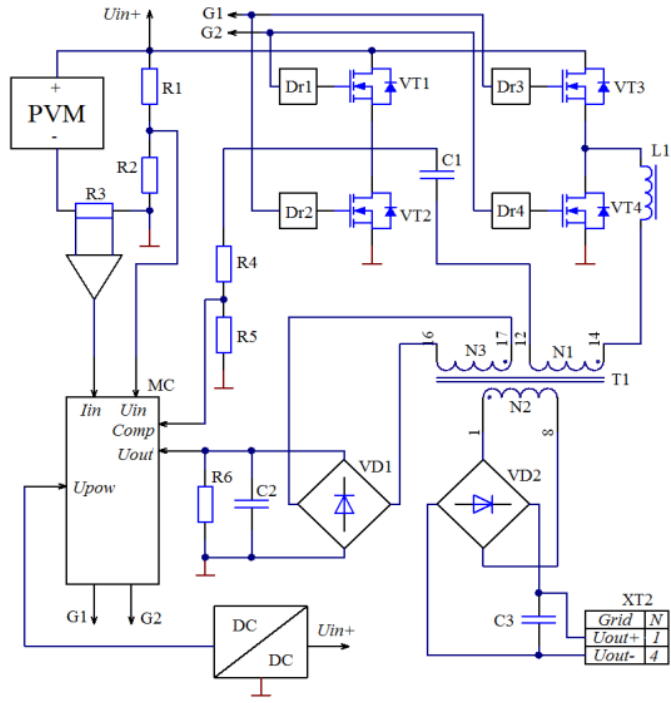

(a)

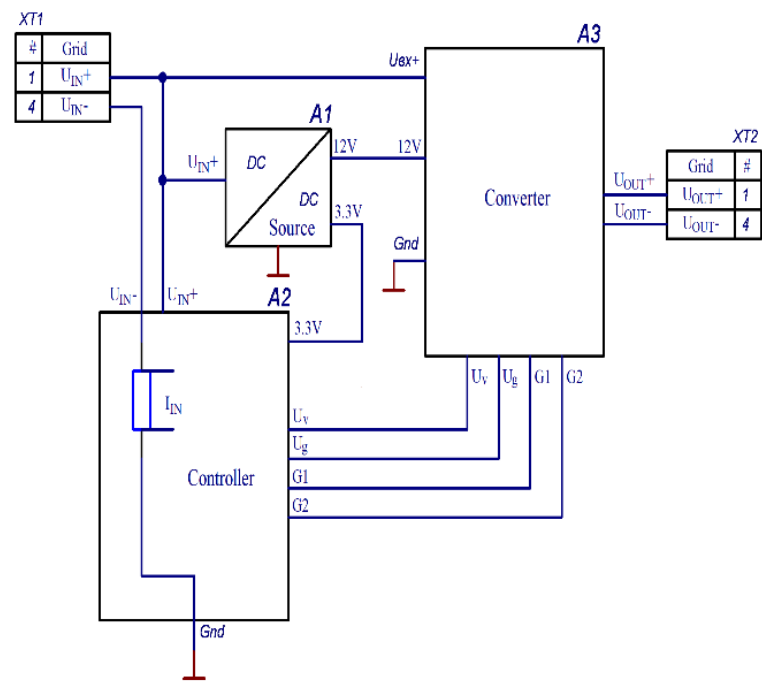

(b)

Figure 7. Functional electric (a) and principal electric (b) circuit of the DC-DC converter

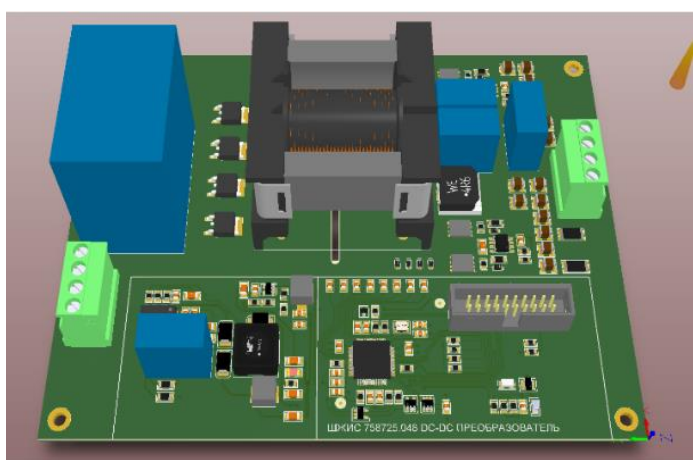

(a)

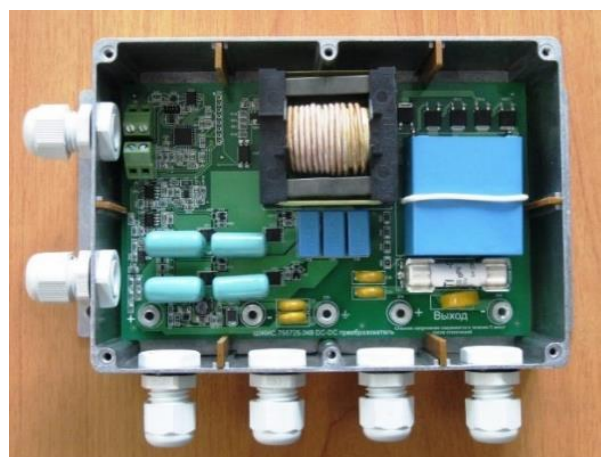

(b)

Figure 8. Circuit board 3D model (a) and manufactured (b) DC-DC converter 


\section{CONCLUSION}

Presented design of regulated resonance converter represents a perspective scheme solution that will allow to obtain maximized efficiency electric energy generation a photovoltaic energy station equipped by hybrid photoenergy modules on the silicon solar cells base. Using the resonance transformation solution make easier the solving of finding out the best combination of back-boost converter parameters which based on resonance scheme in a wide range of input and output electric power. The application of computer simulation based on numerous iterations algorithm allow to establish the optimum resonance LLC scheme parameters values. Using of microcontroller allow to implement an effective algorithm for searching and tracking the hybrid modules maximum power point, and also to realize adaptive «dead» time, and continious monotoring in order to finding the capacitive nature of the bridge load. Also implementing microcontroller in converter design will allow integrate it into monitoring network by using cable or wireless connection, like RS-485 or ZigBee protocols, in order to continuous monitoring of modules parameters and ensuring information about the failure.

\section{REFERENCES}

[1] M. Ghadiri, et al. "Experimental investigation of a PVT system performance using nano ferrofluids." Energy Conversion and Management, vol. 103, pp. 468-476, 2015.

[2] R.V. Zaitsev, et al. "Hybrid solar generating module development for high-efficiency solar energy station." Journal of nano- and electronic physics, vol. 10, no. 6, pp. 06017, 2018.

[3] C. Hamilton, et al. "System architecture of a modular direct-DC PV charging station for plug-in electric vehicles." 36th Annual Conference on IEEE Industrial Electronics Society, pp. 2516-2520, November 2010.

[4] R. Martínez, et al. "Fractional DC/DC converter in solar-powered electrical generation systems." 2009 IEEE Conference on Emerging Technologies \& Factory Automation, pp. 1-6, September 2009.

[5] R.V. Zaitsev, et al. "Development of hybrid solar generating module for high-efficiency solar energy station." First Ukraine Conference on Electrical and Computer Engineering, Kiyv, Ukraine, pp. 360-364, June 2017.

[6] S.N. Singh, et al. "Selection of non-isolated DC-DC converters for solar photovoltaic system." Renewable and Sustainable Energy Reviews, vol. 76, pp. 1230-1247, 2017.

[7] N.H. Baharudin, et al. "Topologies of DC-DC converter in solar PV applications." Indonesian Journal of Electrical Engineering and Computer Science, vol.8, no. 2, pp. 368-374, 2017.

[8] J. A. N. D. Ang, et al. "Development of a DC-DC converter with Current Mode Control for multi-source renewable energy harvesting system.” 2016 IEEE region 10 conference, pp. 556-559, November 2016.

[9] T.K. Mohapatra, et al. "A novel non-isolated positive output voltage buck-boost converter." World Journal of Engineering, vol. 16, no. 1, pp. 201-211, 2019.

[10] R. Tirumala, et al., U.S. Patent No. 10,560,013, Washington, DC: U.S. Patent and Trademark Office.

[11] L. Callegaro, et al., "A simple smooth transition technique for the noninverting buck-boost converter." IEEE Transactions on Power Electronics, vol. 33, no. 6, pp. 4906-4915, 2017.

[12] S. Siouane, et al. "Open-switch fault-tolerant operation of a two-stage buck/buck-boost converter with redundant synchronous switch for PV systems." IEEE Transactions on Industrial Electronics, vol .66, no. 5, pp. 3938-3947, 2018.

[13] D. Vinnikov, et al. "Comparison of performance of phase-shift and asymmetrical Pulsewidth modulation techniques for the novel galvanically isolated buck-boost DC-DC converter for photovoltaic applications." IEEE Journal of Emerging and Selected Topics in Power Electronics, vol. 5, no. 2, pp. 624-637, 2016.

[14] L. Jun-Young, et al. "An Isolated DC/DC Converter Using High-Frequency Unregulated Resonant Converter for Fuel Cell Applications.” IEEE Transactions on Industrial Electronics, vol. 58, no. 7, pp. 2926-2934, 2011.

[15] K. Jin, et al. "Hybrid full-bridge three-level LLC resonant converter-A novel DC-DC converter suitable for fuelcell power system.",IEEE Transactions on Industrial Electronics, vol. 53, no, 5, pp. 1492-1503, 2006.

[16] H.S. Choi, et al. "Design consideration of half-bridge LLC resonant converter." Journal of Power Electronics, vol. 7, no. 1, pp. 13-20, 2007

[17] E.S. Glitz, et al, "LLC converters: Beyond datasheets for MOSFET power loss estimation", 2018 IEEE Applied Power Electronics Conference and Exposition, pp. 464-468, March 2018.

[18] B. Yang, et al. "LLC resonant converter for front end DC/DC conversion." Seventeenth Annual IEEE Applied Power Electronics Conference and Exposition, vol. 2, pp. 1108-1112, March 2002.

[19] J.M. Kwon, et al. "Three-phase photovoltaic system with three-level boosting MPPT control." IEEE Transactions on Power Electronics, vol. 23, no. 5, pp. 2319-2327, 2008.

[20] K. Kumar, et al. "Analysis of high voltage-gain hybrid DC-DC power converter with RBFN based MPPT for renewable photovoltaic applications." 2017 IEEE Conference on Energy Conversion, pp. 294-299, October 2017.

[21] S. Tian, et al. "Equivalent circuit modeling of LLC resonant converter." IEEE Transactions on Power Electronics, Early Access, 2020.

[22] H. Wang, et al. "A PWM LLC type resonant converter adapted to wide output range in PEV charging applications." IEEE Transactions on Power Electronics, vol. 33, no. 5, pp. 3791-3801, 2017.

[23] J. Ma, et al. "Investigation on optimal parameter selection for LLC half-bridge resonant converter based on FHA., Turkish Journal of Electrical Engineering \& Computer Sciences, vol. 26, no. 2, pp. 895-905, 2018. 
[24] C. Cecati, et al. "DC nanogrid for renewable sources with modular DC/DC LLC converter building block." IET Power Electronics, vol. 10, no. 5, pp. 536-544, 2016.

[25] X. He, et al. "Resonance Parameter of Variable Mode LLC Converter for Auxiliary Converter." 2019 10th International Conference on Power Electronics and ECCE Asia, pp. 1-6, May 2019.

[26] P. Han, et al. "Research on High Efficiency LLC DC-DC Converter Based on SiC MosFet." 2018 International Power Electronics Conference, pp. 2714-2717, May 2018.

[27] M.G. Khrypunov, et al., "Amplitude-time Characteristics of Switching in Thin Films of Cadmium Telluride", Journal of nano- and electronic physics, vol. 10, no. 1, pp. 01016, 2018.

[28] P.C. Pasc, et al. "SCADA system for solar MPPT controller monitoring." Procedia Technology, vol. 22, pp. 803$807,2016$.

[29] R.V. Zaitsev, et al. "Hybrid Solar Generating Module." 2017 IEEE International Young Scientists Forum on Applied Physics and Engeneering, pp. 112-115, Jctober 2017.

[30] L. Yan, et al. "Monitoring and fault diagnosis system of wind-solar hybrid power station based on ZigBee and BP neural network." Australian Journal of Mechanical Engineering, vol. 16, pp. 54-60, 2018.

\section{BIOGRAPHIES OF AUTHORS}
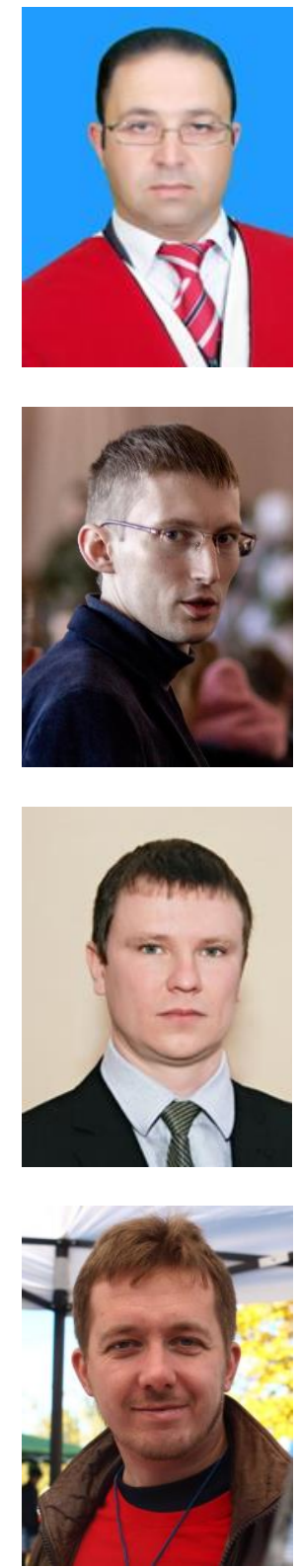

Dr. Mohamed Zaidan Qawaqzeh

PhD, Assistant Professor Mohamed Qawaqzeh graduated from The Eastern Ukrainian State University in 2001, and was qualified as an Electrical Engineer. He received his $\mathrm{PhD}$ in Electric Engineering (Electric Machinery and Apparatus) from Donetsk National Technical University in 2006. Presently, he is an Assistant Professor of Faculty of Engineering, Al-Balqa Applied University (Jordan). His research interests are in the area of power engineering, Smart Grid, Renewable energy.

\section{Dr. Roman Zaitsev}

Doctor Engineering Sciences (Dr. habil.), Associate Professor Roman Zaitsev received the M.Sc. degree in physical materials science from the National Technical University "Kharkiv Politechnic Institute", Kharkiv, Ukraine, in 2009, and the Doctor of Engineering Sciences degree from the Institute of Electrophysics \& Radiation Technologies, Kharkiv, Ukraine, in 2019, all in renewable energy. Presently, he is a Head of Materials for Electronics and Solar Cells department. He is the author of two books, more than 200 articles and more than 10 inventions. His research interests include the renewable energy, solar energy, physics of solar cells, new type of solar cells and mudules, microcontrollers, automation system, embedded system, measuring systems.

\section{Dr. Oleksandr Miroshnyk}

Doctor Technical Sciences (Dr. habil.), Professor Oleksandr Miroshnyk received the M.Sc. degree from the Kharkiv State Technical University of Agriculture, Kharkiv, Ukraine, in 2004, and the Doctor of Technical Sciences degree from the National Technical University "Kharkiv Politechnic Institute", Kharkiv, Ukraine, in 2016, all in electrical power engineering. He is the author of three books, more than 150 articles, and more than 30 inventions. His research interests include the Smart Grid, renewable energy, quality of electrical energy, losses of electrical energy, overhead power lines monitoring, power system automation.

Dr. Mykhailo Kirichenko

PhD Mykhailo Kirichenko received the M.Sc. degree in in physical materials science from the National Technical University "Kharkiv Politechnic Institute", Kharkiv, Ukraine, in 2006, and the $\mathrm{PhD}$ degree in physics of thin film devices from the Institute of Electrophysics \& Radiation Technologies, Kharkiv, Ukraine, in 2011. Presently, he is a Senior Researcher of Materials for Electronics and Solar Cells department. He is the author of two books, more than 200 articles and more than 10 inventions. His research interests include the renewable energy, solar energy, physics of solar cells, new type of solar cells and mudules, microcontrollers, automation system, embedded system, measuring systems 


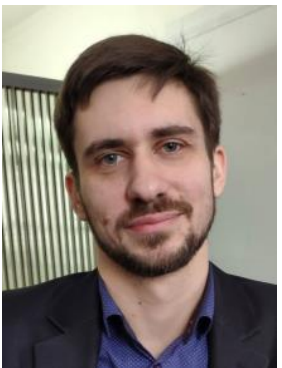

Dr. Dmytro Danylchenko

PhD Dmytro Danylchenko, graduated from The Zaporizhzhya National Technical University, Zaporizhzhya, Ukraine, in 2012, and was qualified as an Electrical Engineer. He received his $\mathrm{PhD}$ in Electric Engineering (power stations, systems and networks) from the National Technical University "Kharkiv Politechnic Institute", Kharkiv, Ukraine, in 2018. Presently, he is an Assistant Professor of Institute of Power Engineering, Electronics and Electromechanics, National Technical University "Kharkiv Politechnic Institute", Kharkiv, Ukraine. His research interests are in the area of power engineering, digitalization of the electric power industry, renewable energy.

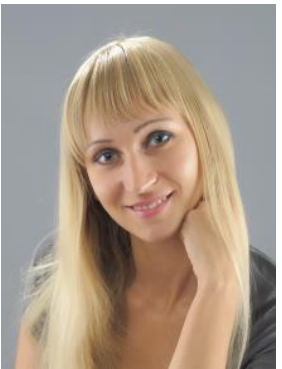

Dr. Liliia Zaitseva

PhD Liliia Zaitseva received the M.Sc. degree in non-destructive testing devices and systems from the National Technical University "Kharkiv Politechnic Institute", Kharkiv, Ukraine, in 2009, and the PhD degree in physics of thin film devices from the Institute of Electrophysics \& Radiation Technologies, Kharkiv, Ukraine, in 2015. She is the author of more than 50 articles and 2 inventions. Her research interests include the renewable energy, solar energy, physics of solar cells, physics of semiconductor thin film, testing devices, measuring systems. 